\title{
Cyclometalated Iridium(III) Complexes Containing 2-Phenylbenzo[d] oxazole Ligand: Synthesis, X-ray Crystal Structures, Properties and DFT Calculations
}

\author{
Xiao-Han Yang, ${ }_{1}^{1}$ Qian Zhang, ${ }^{1}$ Hui Peng, ${ }^{1}$ Zi-Cen Zuo, ${ }^{1}$ Ding Yuan, ${ }^{1}$ Yan Chen, \\ Qin Chen, ${ }^{1}$ Guang-Ying Chen, ${ }^{2}$ Zhi-Gang Niu ${ }^{1,2}$ and Gao-Nan $\mathrm{Li}^{1, *}$ \\ ${ }^{1}$ Key Laboratory of Electrochemical Energy Storage and Energy Conversion of Hainan Province, \\ College of Chemistry and Chemical Engineering, Hainan Normal University, Haikou 571158, PR China \\ ${ }^{2}$ Key Laboratory of Tropical Medicinal Plant Chemistry of Ministry of Education, Hainan Normal University, \\ Haikou 571158, PR China \\ *Corresponding author: E-mail: ligaonan2008@163.com
}

Received: 11-25-2018

\begin{abstract}
Two new iridium(III) complexes were synthesized and fully characterized, [(bo $)_{2} \operatorname{Ir}\left(\right.$ pzpy)] (2a) and $\left[(\text { bo })_{2} \operatorname{Ir}(\right.$ pzpyz) (2b) (where bo = 2-phenylbenzo[d] oxazole, pzpy = 2-(1H-pyrazol-3-yl)pyridine, pzpyz = 2-(1H-pyrazol-3-yl)pyrazine). The single crystal structures of $\mathbf{2} \mathbf{a}-\mathbf{2} \mathbf{b}$ have been determined. Considering the relationship between their structures and photophysical properties, DFT calculations have been used to further support this inference. $\operatorname{These} \operatorname{Ir}(\mathrm{III})$ complexes emit from the excited state of ${ }^{3} \mathrm{MLCT} /{ }^{3} \mathrm{LLCT}$ in the green and yellow region, and the quantum yields in the degassed $\mathrm{CH}_{2} \mathrm{Cl}_{2}$ solution at room temperature are $35.2 \%$ and $46.1 \%$. Theoretical and experimental results show that iridium(III) complexes $\mathbf{2} \mathbf{a}-\mathbf{2} \mathbf{b}$ are promising phosphorescent material.
\end{abstract}

Keywords: Iridium(III) complex; Crystal structure; 2-phenylbenzo[d]oxazole; Photoluminescence; DFT calculation

\section{Introduction}

Neutral mononuclear cyclometalated iridium complexes have been found to be suitable for use in organic light emitting diodes (OLEDs). ${ }^{1-3}$ The privileged use is due to their interesting luminescence properties, ${ }^{4-5}$ such as high quantum yields, long excited-state lifetimes, and tunable emission color over the entire visible spectrum. ${ }^{6-7}$ Most often, the variation of their emission color was largely governed by the cyclometalated and/or ancillary ligands structures.

2-phenylbenzo[d]oxazole (bo) is one typical ligand framework for constructing Ir(III) complexes, and can be used to fine-tune the emission color of complexes by judicious modification. ${ }^{8-10}$ For example, in 2015, we reported $\operatorname{Ir}(\mathrm{bo})_{2}(\mathrm{acac})$ derivatives with substituents on the benzoxazole ring and their emissions covered a narrow range from 560 to $566 \mathrm{~nm} .{ }^{11}$ The color adjusting by the change of cyclometalated ligands structures were not very satisfactory, although the quantum yield was up to $53.5 \%$. Afterward, we designed a series of bo-based iridium(III) com- plexes with different $\mathrm{N}^{\wedge} \mathrm{O}$ ancillary ligands. They exhibited a wide range of emission wavelengths $\left(\lambda_{\max }=531-598\right.$ $\mathrm{nm})$ with high quantum yields (19\%-94\%). ${ }^{12}$ The research findings showed that the structures of ancillary ligands have obvious effect on tuning the emission color of bobased iridium(III) complexes. Therefore, we wanted to further investigate other types of ancillary ligands. In this paper, we design two $\mathrm{N}^{\wedge} \mathrm{N}$ ancillary ligands ( $\mathbf{a}$ and $\mathbf{b}$ ) and synthesize two bo-based iridium(III) complexes (2a and 2b) (Scheme 1). The photophysical and electrochemical properties of these complexes were investigated, and the lowest energy electronic transitions were analyzed based on density functional theory (DFT) and time-dependent DFT (TDDFT).

\section{Experimental}

\section{1. Materials and Instrumentations}

2-aminophenol and benzaldehyde were obtained from Hebei Guanlang Biotechnology Co., Ltd.. 2-(prop-1- 

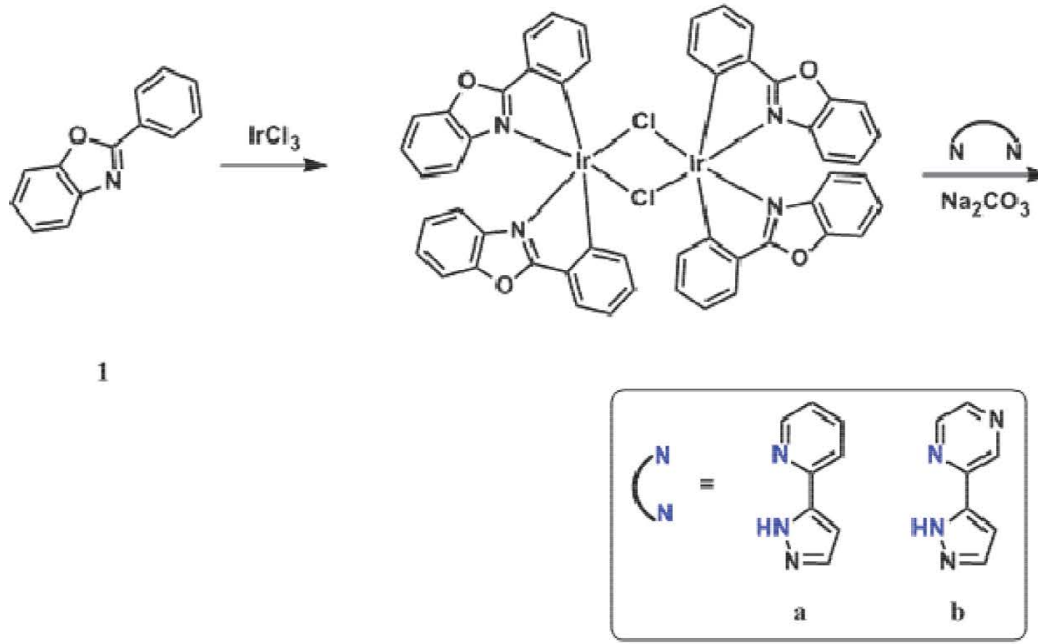
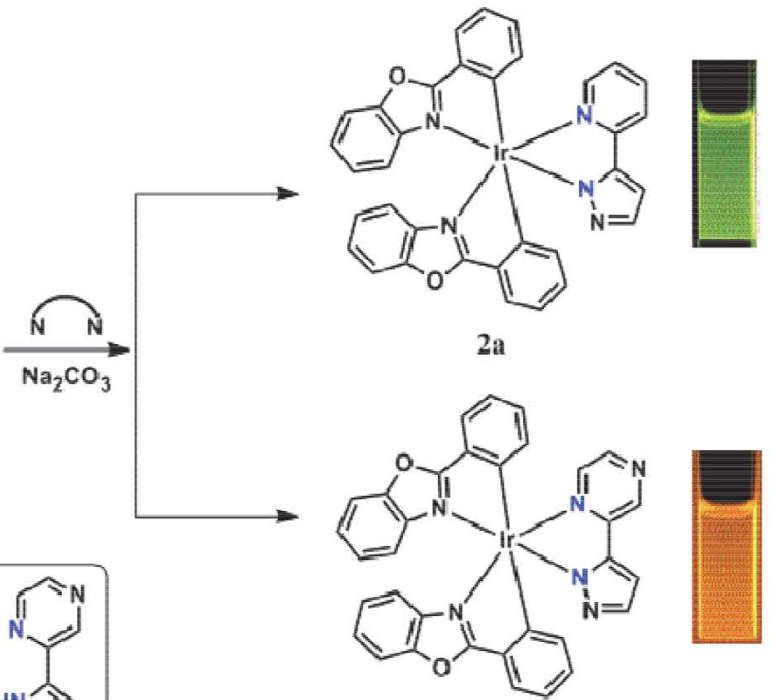

$2 b$

Scheme 1. Synthetic routes of $\operatorname{Ir}(\mathrm{III})$ complexes $\mathbf{2 a - 2 b}$

en-2-yl)pyridine, 2-(prop-1-en-2-yl)pyrazine and 1,1-dimethoxy-N,N-dimethylmethanamine were obtained from Dayang Chemicals Co., Ltd., SAGECHEM LIMITED and Sigma-Aldrich, respectively. $\mathrm{IrCl}_{3} \cdot 3 \mathrm{H}_{2} \mathrm{O}$ was industrial products. The target ligands 2-phenylbenzo[d]oxazole (1), 2-(1H-pyrazol-3-yl)pyridine (a) and 2-(1H-pyrazol-3-yl) pyrazine (b) were prepared according to the literature method. ${ }^{13-15}$ All commercial chemicals were used without further purification unless otherwise stated. Solvents were dried and degassed following standard procedures. ${ }^{1} \mathrm{H}$ NMR spectra were recorded on a Bruker AM $400 \mathrm{MHz}$ instrument. Chemical shifts were reported in ppm relative to $\mathrm{Me}_{4} \mathrm{Si}$ as internal standard. UV-Vis spectra were recorded on a Hitachi U3900/3900H spectrophotometer. Fluorescence spectra were carried out on a Hitachi F-7000 spectrophotometer. The FTIR spectra were taken on a Nicolet 6700 FTIR spectrometer $\left(400-4000 \mathrm{~cm}^{-1}\right)$ with $\mathrm{KBr}$ pellets.

\section{2. Synthesis of (bo) $)_{2} \operatorname{Ir}$ (pzpy) (2a)}

A mixture of $\mathrm{IrCl}_{3} \cdot 3 \mathrm{H}_{2} \mathrm{O}(306 \mathrm{mg})$ and 2-phenylbenzo[d] oxazole $(500 \mathrm{mg}$ ) in $15 \mathrm{~mL}$ of 2-ethoxyethanol and $\mathrm{H}_{2} \mathrm{O}(\mathrm{v}: \mathrm{v}=2: 1)$ was heated at $120^{\circ} \mathrm{C}$ for 12 hours under $\mathrm{N}_{2}$. After cooling to room temperature, the yellow precipitate was collected by filtration and washed with cooled ether and $\mathrm{MeOH}$. After drying, the crude product of chlorine bridged dimer complex $\left[(\mathrm{bo})_{2} \operatorname{Ir}(\mu-\mathrm{Cl})\right]_{2}$ can be used in the next step without further purification. This was followed by crude chlorine bridged dimer (207 mg), 2-(1H-pyrazol-3-yl)pyridine (54 mg, $2.2 \mathrm{eq})$ and $\mathrm{Na}_{2} \mathrm{CO}_{3}$ (88 mg, $5.0 \mathrm{eq})$. In 2-ethoxyethanol $(10 \mathrm{ml})$, the mixture was heated at $120^{\circ} \mathrm{C}$ under $\mathrm{N}_{2}$ for 12 hours. After removing the solvent, the mixture was poured into water, extract- ed three times with $\mathrm{CH}_{2} \mathrm{Cl}_{2}$, and then evaporated. The residue was purified by flash column chromatography (DCM: $\mathrm{MeOH}=50: 1)$ to obtain iridium complex $2 \mathbf{a}$ as a yellow solid (76 mg, yield: $64.6 \%) .{ }^{1} \mathrm{H}$ NMR $\left(400 \mathrm{MHz}, \mathrm{CDCl}_{3}\right) \delta$ $7.93(\mathrm{~s}, 1 \mathrm{H}), 7.80-7.67(\mathrm{~m}, 4 \mathrm{H}), 7.56(\mathrm{dd}, J=17.5,9.0 \mathrm{~Hz}$, $2 \mathrm{H}), 7.31(\mathrm{~d}, J=6.9 \mathrm{~Hz}, 2 \mathrm{H}), 7.14(\mathrm{~s}, 2 \mathrm{H}), 6.96(\mathrm{dd}, J=44.3$, $7.6 \mathrm{~Hz}, 6 \mathrm{H}), 6.71(\mathrm{~s}, 2 \mathrm{H}), 6.65(\mathrm{~s}, 1 \mathrm{H}), 5.97(\mathrm{dd}, J=16.8,7.8$ $\mathrm{Hz}, 2 \mathrm{H})$. MS (ESI): $\mathrm{m} / \mathrm{z}=726.0\left[\mathrm{M}^{+}\right]$. IR $\left(\mathrm{KBr}, \mathrm{cm}^{-1}\right)$ : 2856(w), 1649(w), 1592(vs), 1520(m), 1448(vs), 1387(s), 1252(w), 1188(w), 1130(s), 1084(s) 1045(w), 816(w), 742(m), 474(m). Calcd for $\mathrm{C}_{33} \mathrm{H}_{21} \mathrm{IrN}_{5} \mathrm{O}_{2}$ (\%): C 56.34, H 3.06, N 9.66; Found: C 55.67, H 3.22, N 9.37.

\section{3. Synthesis of $(\text { bo })_{2} \operatorname{Ir}($ pzpyz) (2b)}

The complex $\mathbf{2 b}$ (70 mg, yield: 59.4\%) was obtained using 2-(1H-pyrazol-3-yl)pyrazine instead of 2-(1H-pyrazol-3-yl)pyridine by a method similar to that of preparing 2a. ${ }^{1} \mathrm{H}$ NMR $\left(400 \mathrm{MHz}, \mathrm{CDCl}_{3}\right) \delta 9.04(\mathrm{~s}, 1 \mathrm{H}), 8.22(\mathrm{~d}, J=$ $2.3 \mathrm{~Hz}, 1 \mathrm{H}), 7.92(\mathrm{~s}, 1 \mathrm{H}), 7.82(\mathrm{dd}, J=16.8,9.6 \mathrm{~Hz}, 3 \mathrm{H})$, $7.69-7.56(\mathrm{~m}, 2 \mathrm{H}), 7.42-7.33(\mathrm{~m}, 2 \mathrm{H}), 7.19(\mathrm{t}, J=7.8 \mathrm{~Hz}$, $1 \mathrm{H}), 7.14-6.91(\mathrm{~m}, 5 \mathrm{H}), 6.88(\mathrm{~s}, 1 \mathrm{H}), 6.74(\mathrm{~d}, J=7.5 \mathrm{~Hz}$, $1 \mathrm{H}), 6.65(\mathrm{~d}, J=7.6 \mathrm{~Hz}, 1 \mathrm{H}), 6.01(\mathrm{dd}, J=26.9,8.0 \mathrm{~Hz}$, $2 \mathrm{H})$. MS (ESI): $\mathrm{m} / \mathrm{z}=727.0\left[\mathrm{M}^{+}\right]$. IR $\left(\mathrm{KBr}, \mathrm{cm}^{-1}\right): 2962(\mathrm{~m})$, 2920(m), 2854(w), 1595(m), 1520(m), 1452(m), 1387(m), 1335(w), 1259(s), 1092(vs), 1030(vs), 804(vs), 742(m), 476(w). Calcd for $\mathrm{C}_{33} \mathrm{H}_{21} \mathrm{IrN}_{6} \mathrm{O}_{2}$ (\%): C 54.61, H 2.92, N 11.58; Found: C 54.95, H 3.08, N 11.04.

\section{4. Crystallographic Studies}

X-ray diffraction data were collected with an Agilent Technologies Gemini A Ultra diffractometer equipped 
with graphite-monochromated Mo $\mathrm{K} \alpha$ radiation $(\lambda=$ $0.71073 \AA$ ) at room temperature. Data collection and reduction were processed with CrysAlisPro software. ${ }^{16}$ The structure was solved and refined using Full-matrix leastsquares based on $F^{2}$ with program SHELXS-97 and SHELXL-97 ${ }^{17}$ within Olex2. ${ }^{18}$ All non-hydrogen atoms were found in alternating difference Fourier syntheses and least-squares refinement cycles and, during the final cycles, refined anisotropically. Hydrogen atoms were placed in calculated positions and refined as riding atoms with a uniform value of $U$ iso.

\section{5. Computational Method}

The geometry of complexes $\mathbf{2 a - 2} \mathbf{b}$ was optimized starting from the X-ray data by the DFT (density functional theory) method with B3LYP (Becke three-parameter Lee-Yang-Parr) hybrid density functional theory and the $6-31 G^{*}$ basis set. All calculations were carried out with Gaussian 09 software package. ${ }^{19}$

\section{Results and Discussion}

\section{1. Description of Crystal Structure}

The single crystal structures of $\mathbf{2} \mathbf{a}-\mathbf{2} \mathbf{b}$ were obtained by X-ray diffraction studies, and ORTEP diagrams are
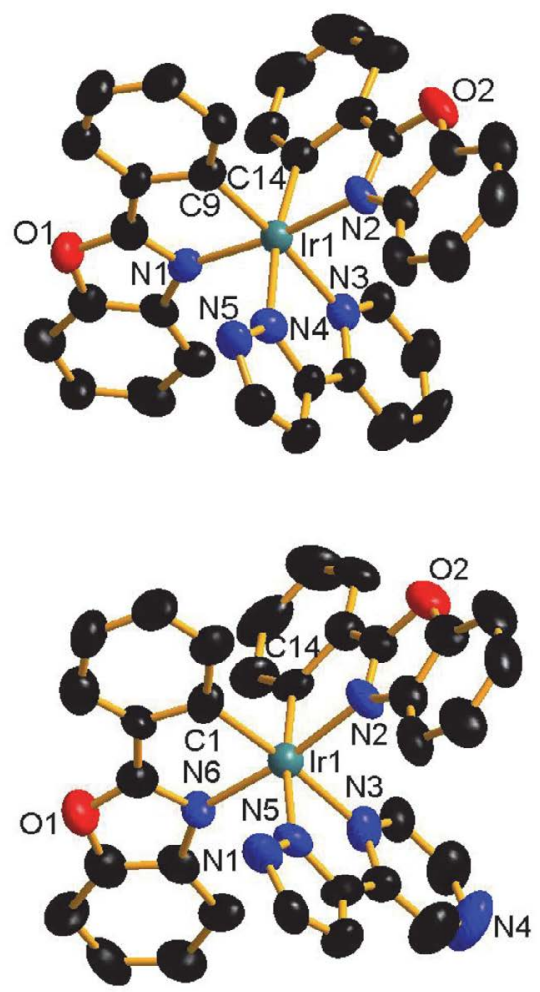

Fig. 1. ORTEP view of $\mathbf{2 a}$ (up) and $\mathbf{2} \mathbf{b}$ (down) with the thermal ellipsoids drawn at the $50 \%$ probability level. Hydrogen atoms and solvent molecules are omitted for clarity. shown in Fig. 1. The crystallographic data and structural details are given in Table 1. The selected bond lengths and bond angles are collected in Table S1.

For the structures of these complexes, the Ir(III) centre adopts a twisted octahedral geometry, and the $\mathrm{C}^{\wedge} \mathrm{N}$ ligands are in cis-C,C' and trans-N,N' configurations. The Ir-N average bond lengths of $\mathbf{2 a}(2.077 \AA)$ and $\mathbf{2 b}(2.100 \AA)$ are longer than the Ir-C average bond lengths of $2 \mathbf{a}$ $(2.019 \AA)$ and $\mathbf{2 b}(2.041 \AA)$, which are reported in other iridium complexes. ${ }^{20}$ Furthermore, the Ir-N bonds between the iridium and $\mathrm{N}^{\wedge} \mathrm{N}$ ligands $(2.081-2.152 \AA)$ are longer than those between the iridium and $\mathrm{C}^{\wedge} \mathrm{N}$ ligands (2.037-2.073 $)$, consistent with strong trans influence of the $\mathrm{C}^{\wedge} \mathrm{N}$ ligands. The octahedral para-orbital angles range from $171.0(5)^{\circ}$ to $174.6(5)^{\circ}$ for $2 \mathbf{a}$ and from $171.9(4)^{\circ}$ to $174.9(4)^{\circ}$ for $\mathbf{2 b}$, which is close to a straight line. The metric parameters of the two iridium complexes are similar owing to the same cyclometalated ligands and analogous ancillary ligands.

Table 1. Crystallographic data for complexes $\mathbf{2 a - 2 b}$.

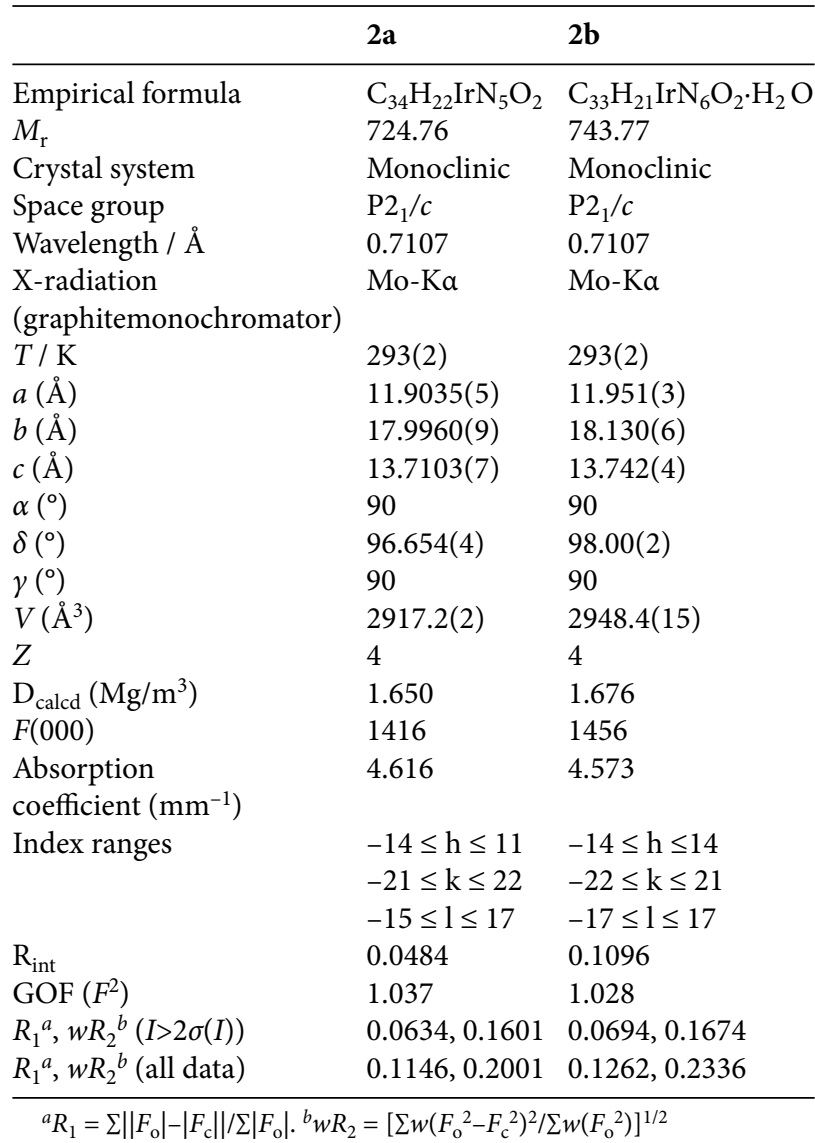

\section{2. Electronic Absorption Spectra}

The UV-Vis absorption spectra of $\mathbf{2} \mathbf{a}-\mathbf{2} \mathbf{b}$ were recorded at room temperature in $\mathrm{CH}_{2} \mathrm{Cl}_{2}$ solutions, as shown in Fig. 2, and the data are summarized in Table 2. All of the 
complexes exhibit intense absorption bands in the ultraviolet region at wavelengths below $310 \mathrm{~nm}$, which are assigned to the spin-allowed $\pi-\pi^{\star}$ transitions on the $\mathrm{C}^{\mathrm{U}} \mathrm{N}$ main ligands and the $\mathrm{N}^{\wedge} \mathrm{N}$ ancillary ligands. The weaker absorption bands in the range $350-450 \mathrm{~nm}$ are likely attributed to metal-to-ligand charge-transfer transitions $\left({ }^{1}\right.$ MLCT and ${ }^{3}$ MLCT). ${ }^{21-22}$ Compared with complex 2a, complex $\mathbf{2 b}$ has a red-shifted, which may be caused by the ancillary ligand. This speculation will be confirmed by electrochemical analysis and DTF calculations.

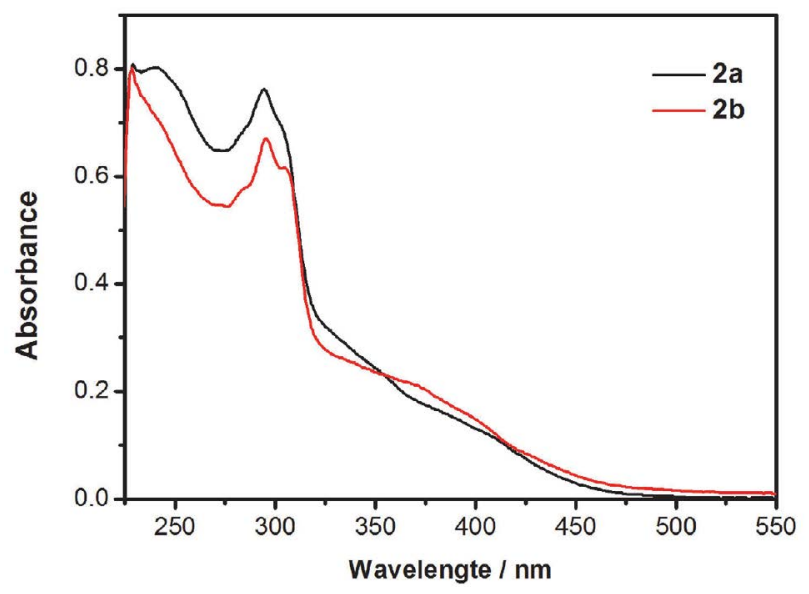

Fig. 2. UV-Vis absorption spectra of $\mathbf{2 a - 2} \mathbf{b}$, recorded in $\mathrm{CH}_{2} \mathrm{Cl}_{2}$ at room temperature.

\section{3. Emission Properties}

The photoluminescence emission spectra of iridium complexes $\mathbf{2 a - 2 b}$ in degassed $\mathrm{CH}_{2} \mathrm{Cl}_{2}$ solution at room temperature and corresponding data are described in Fig. 3 and Table 2, respectively. Complex 2a exhibits green phosphorescence with the broad emission maxima peak at $518 \mathrm{~nm}$ and a shoulder peak at $547 \mathrm{~nm}$, whereas $2 \mathbf{b}$ is yellow emissive with the broad emission maxima peak at $529-552 \mathrm{~nm}$. For their emission, the excited state of $\mathbf{2 a}$ is attributed to the mixing of ${ }^{3} \mathrm{MLCT}$ and ${ }^{3} \mathrm{LC},{ }^{23}$ while that of $\mathbf{2 b}$ is mainly attributed to ${ }^{3}$ MLCT. ${ }^{24}$ As expected, the emission band of $\mathbf{2 b}$ has red-shifted with respect to $\mathbf{2 a}$ due to different ancillary ligands, which is consistent with absorption analysis. In addition, the quantum yields of $\mathbf{2 a}$ and $\mathbf{2 b}$ in solution at room temperature were measured to

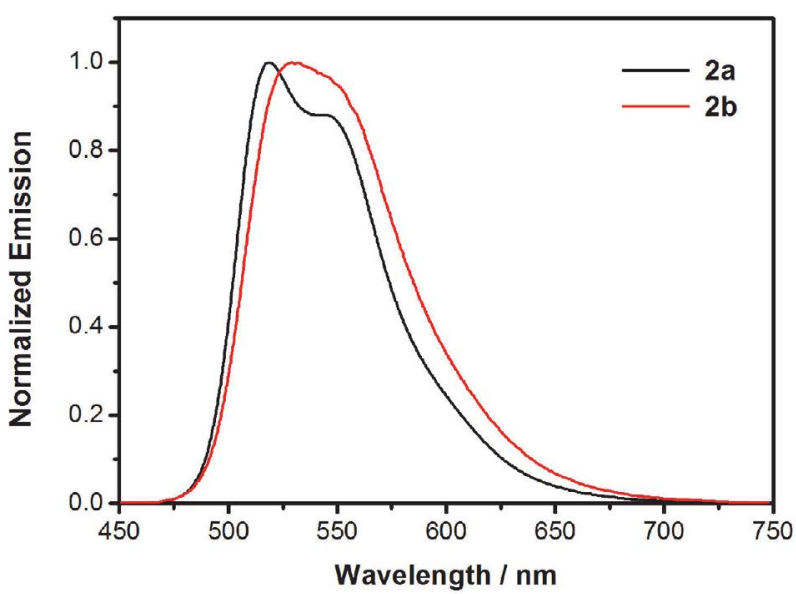

Fig. 3. The emission spectra of $\mathbf{2 a}-\mathbf{2} \mathbf{b}$ in $\mathrm{CH}_{2} \mathrm{Cl}_{2}$ at room temperature.

be $35.2 \%$ and $46.1 \%$ with reference to $f a c-\operatorname{Ir}(\mathrm{ppy})_{3}(\Phi=$ $0.40) .{ }^{25}$

\section{4. Theoretical Calculations}

Density functional theory (DFT) and time-dependent DFT (TD DFT) calculations have been performed on the complexes $\mathbf{2} \mathbf{a}-\mathbf{2 b}$ to obtain an insight into the lowest energy electron transition. The most representative molecular front orbital diagram of these complexes is shown in Fig. 4 . The calculated spin-allowed electron transitions are provided in Table 3 and compared with the experimental absorption spectra data. The electron density distribution data are summarized in Table S2.

As shown in Fig. 4, the HOMOs of these complexes are mainly located on the metal center and $\mathrm{C}^{\wedge} \mathrm{N}$ ligands. Meanwhile, the LUMO of $\mathbf{2 a}$ is mostly dominated on $\mathrm{C}^{\wedge} \mathrm{N}$ ligands, while LUMO of $\mathbf{2 b}$ is mainly located on the whole ancillary ligands. In addition, the LUMO+1s of these complexes are primarily centered on the $\mathrm{C}^{\wedge} \mathrm{N}$ main ligands, while HOMO-1s are delocalized over the metal center, $\mathrm{C}^{\wedge} \mathrm{N}$ ligands and ancillary ligands. The theoretical calculation of DFT shows that the lowest energy spin-allowed transitions of $\mathbf{2 a - 2 b}$ come from HOMO $\rightarrow$ LUMO/ LUMO +1 and $\mathrm{HOMO} \rightarrow \mathrm{LUMO}+1 / \mathrm{HOMO}-1 \rightarrow \mathrm{LUMO}$ transitions (Table 3), and therefore attributed to metal-to-ligand charge transfer transition and ligand-to-ligand $\pi-\pi^{*}$ transition. These calculations support the photophysical properties discussed above.

Table 2. Photophysical and electrochemical data of complexes $\mathbf{2 a - 2 b .}$

\begin{tabular}{|c|c|c|c|c|c|c|}
\hline Complex & $\begin{array}{c}\text { Absorption }^{a} \\
\lambda_{a b s}(\mathbf{n m})\end{array}$ & $\begin{array}{c}\text { Emission }^{a} \\
\lambda_{e m}(\mathbf{n m})\end{array}$ & $\begin{array}{c}\Phi_{\mathrm{em}}^{b} \\
(\%)\end{array}$ & $\begin{array}{l}E_{o x}{ }^{a} \\
(\mathrm{~V})\end{array}$ & $\begin{array}{l}\text { HOMO }^{c} \\
\quad(\mathrm{eV})\end{array}$ & $\begin{array}{c}\text { HOMO }^{\alpha} \\
(\mathrm{eV})\end{array}$ \\
\hline $2 a$ & $229,240,295$ & $518,547(\mathrm{sh})$ & 35.2 & 1.57 & -6.37 & -5.44 \\
\hline $2 b$ & $228,295,308(\mathrm{sh})$ & 529,552 & 46.1 & 1.62 & -6.42 & -5.54 \\
\hline
\end{tabular}

${ }^{a}$ Data were collected from degassed $\mathrm{CH}_{2} \mathrm{Cl}_{2}$ solutions at room temperature. ${ }^{b} f a c$ - $\mathrm{Ir}(\mathrm{ppy})_{3}$ as referenced standard $(0.4) .{ }^{25}{ }^{c} \mathrm{HOMO}$ energies are deduced from the equation $\mathrm{HOMO}=-\left(E_{\mathrm{ox}}+4.8 \mathrm{eV}\right) .{ }^{d}$ Obtained from theoretical calculations. 

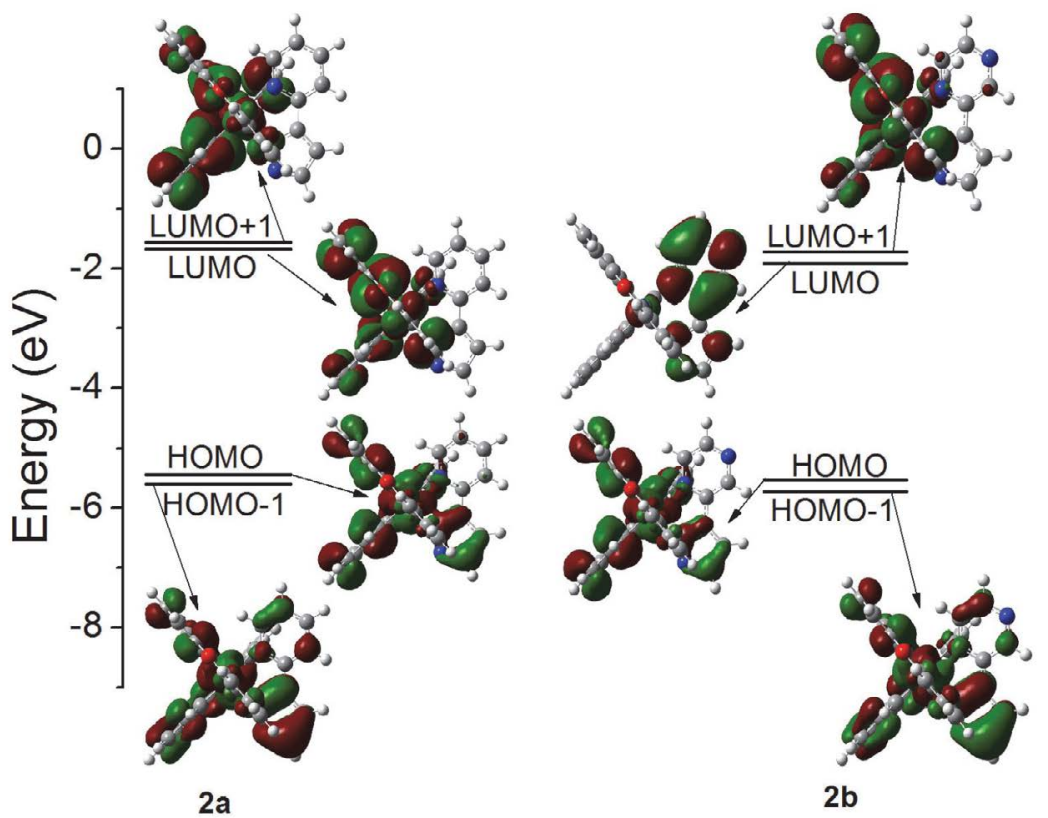

Fig. 4. The frontier molecular orbital energy-level diagrams of $\mathbf{2 a - 2 b}$ from DFT calculations.

Table 3. Main experimental and calculated optical transitions for $\mathbf{2 a - 2 b}$.

\begin{tabular}{|c|c|c|c|c|c|c|}
\hline Complex & Orbital Excitations & Transition & Character & $\begin{array}{c}\text { Oscillation } \\
\text { Strength }\end{array}$ & $\begin{array}{c}\text { Calcd } \\
(\mathrm{nm})\end{array}$ & $\begin{array}{l}\text { Exptl } \\
\text { (nm) }\end{array}$ \\
\hline \multirow[t]{2}{*}{$2 a$} & $\mathrm{HOMO} \rightarrow \mathrm{LUMO}$ & MLCT/LLCT & $\mathrm{d} \pi_{\mathrm{Ir}} / \pi_{\mathrm{bo}} \rightarrow \pi_{\mathrm{bo}}^{*}$ & 0.0802 & 408 & 407 \\
\hline & $\mathrm{HOMO} \rightarrow \mathrm{LUMO}+1$ & MLCT/LLCT & $\mathrm{d} \pi_{\mathrm{Ir}} / \pi_{\mathrm{bo}} \rightarrow \pi_{\mathrm{bo}}^{*}$ & 0.0401 & 393 & \\
\hline \multirow[t]{2}{*}{$2 b$} & $\mathrm{HOMO} \rightarrow \mathrm{LUMO}+1$ & MLCT/LLCT & $\mathrm{d} \pi_{\mathrm{Ir}} / \pi_{\mathrm{bo}} \rightarrow \pi_{\mathrm{bo}}^{*}$ & 0.0242 & 403 & 372 \\
\hline & HOMO- $1 \rightarrow$ LUMO & MLCT/LLCT & $\mathrm{d} \pi_{\mathrm{Ir}} / \pi_{\mathrm{bo}} / \pi_{\text {pzpyz }} \rightarrow \pi_{\text {pzpyz }}^{*}$ & 0.0225 & 397 & \\
\hline
\end{tabular}

\section{5. Electrochemical Properties}

The electrochemical properties of $\mathbf{2} \mathbf{a}-\mathbf{2} \mathbf{b}$ were studied by cyclic voltammetry and shown in Fig. 5 . The corre-

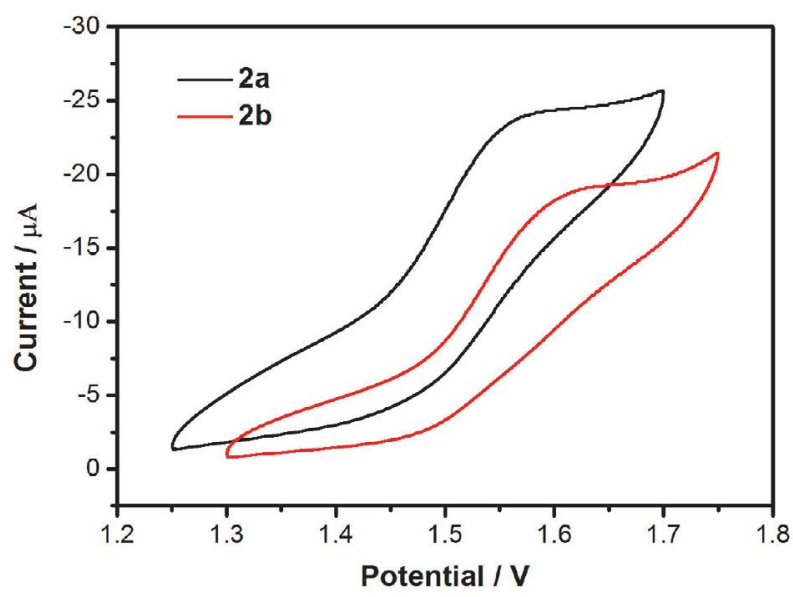

Fig. 5. Cyclic voltammograms for $\mathbf{2 a - 2 b}$ in $\mathrm{CH}_{2} \mathrm{Cl}_{2}$ solution containing $\mathrm{n}-\mathrm{Bu}_{4} \mathrm{NClO}_{4}(0.1 \mathrm{M})$ at a sweep rate of $100 \mathrm{mV} / \mathrm{s}$. sponding electrochemical data and estimated HOMO energy levels are summarized in Table 2 . The complexes $\mathbf{2 a -}$ $2 \mathbf{b}$ exhibit quasi-reversible oxidation peaks at $1.57 \mathrm{~V}$ and $1.62 \mathrm{~V}$, respectively. From DFT calculations (Table S2), HOMO is mainly located on Ir ions $(47.77 \%$ for $2 \mathbf{a}$ and $46.90 \%$ for $\mathbf{2 b})$ and $\mathrm{C}^{\wedge} \mathrm{N}$ ligands $(40.97 \%$ for $\mathbf{2 a}$ and $44.91 \%$ for $\mathbf{2 b}$ ). Thus, their oxidation processes are assigned to Ir (III) to Ir (IV) and some contributions of the $\mathrm{C}^{\wedge} \mathrm{N}$ ligands. ${ }^{26}$ Based on the oxidation potential, the $\mathrm{HOMO}$ energy is derived from the equation $E_{\mathrm{HOMO}}=$ $\left(E_{\mathrm{ox}}+4.8 \mathrm{eV}\right)$, and the trend is consistent with the theoretical calculations (Table 2). From these results, it can be seen that because of the different number of nitrogen atoms in the ancillary ligands, the HOMO level of $\mathbf{2 b}$ is more stable than that of the analogue $2 \mathbf{a}$, and the oxidation process of $\mathbf{2} \mathbf{b}$ is more difficult than that of $\mathbf{2 a}$.

\section{Conclusions}

In summary, the syntheses, characterization, as well as electrochemical, spectroscopic and photophysical prop- 
erties of two new bo-based iridium(III) complexes are reported. The room-temperature phosphorescence of these complexes is tunable from green to yellow depending on the different ancillary ligands. It was also found that as the number of nitrogen atoms increased on the ancillary ligands, the quantum yields became larger and emission became brighter. The DFT calculated results are in good agreement with the actual absorption spectra, indicating that the lowest absorption is assigned to the MLCT/LLCT transition. These results will facilitate the design of new bo-based iridium(III) complexes for highly efficient OLEDs.

\section{Acknowledgments}

This work was supported by the Natural Science Foundation of Hainan Province (218QN236) and Program for Innovative Research Team in University (IRT-16R19).

\section{Supplementary Material}

The selected bonds and angles of complexes $\mathbf{2 a - 2} \mathbf{2}$, the frontier orbital energy and electron density distributions of complexes $\mathbf{2 a - 2} \mathbf{b}$, as well as the FTIR spectra of complexes $\mathbf{2 a - 2 b}$. Crystallographic data for the structural analyses have been deposited in the Cambridge Crystallographic Data Centre, CCDC reference number 1881007 (2a) and 1881008 (2b). Copies of this information may be obtained free of charge from The Director, CCDC, 12 Union Road, Cambridge CB2 1EZ, UK (fax: +44 1223 336033; e-mail: deposit@ccdc.cam. ac.uk).

\section{References}

1. M. C. Gather, A. Köhnen, K. Meerholz, Adv. Mater. 2011, 23, 233-248. DOI:10.1002/adma.201002636

2. C. Fan, C. Yang, Chem. Soc. Rev. 2014, 43, 6439-6469. DOI:10.1039/C4CS00110A

3. G. M. Farinola, R. Ragni, Chem. Soc. Rev. 2011, 40, 34673482. DOI: $10.1039 / \mathrm{c} 0 \mathrm{cs} 00204 \mathrm{f}$

4. L. Flamigni, A. Barbieri, C. Sabatini, B. Ventura, F. Barigelletti, Top. Curr. Chem. 2007, 281, 143-203.

DOI:10.1007/128_2007_143

5. E. Baranoff, E. Orselli, L. Allouche, D. DiCenso, R. Scopelliti, M. Gr€atzel, M. K. Nazeeruddin, Chem. Commun. 2011, 47, 2799-2801. DOI:10.1039/c0cc05029f

6. M. A. Baldo, M. E. Thompson, S. R. Forrest, Nature. 2000, 403, 750-753. DOI:10.1038/35001541

7. E. Matteucci, A. Baschieri, A. Mazzanti, L. Sambri, J. Avila, A. Pertegas, H. J. Bolink, F. Monti, E. Leoni, N. Armaroli, Inorg.
Chem. 2017, 56, 10584-10595.

DOI:10.1021/acs.inorgchem.7b01544

8. X. Li, X. T. Yu, H. J. Chi, Y. Dong, G. Y. Xiao, P. Lei, D. Y. Zhang, Z. Cui, Spectrochim. Acta, Part A. 2013, 116, 473-477. DOI:10.1016/j.saa.2013.07.075

9. X. Li, H. J. Chi, Y. Dong, G. Y. Xiao, P. Lei, D. Y. Zhang, Z. Cui, Opt. Mater. 2013, 36, 265-270.

DOI:10.1016/j.optmat.2013.09.006

10. H. W. Hong, T. M. Chen, Mater. Chem. Phys. 2007, 101, 170176. DOI:10.1016/j.matchemphys.2006.03.011

11. Z.-G. Niu, T. Zheng, Y.-H. Su, P.-J. Wang, X.-Y. Li, F. Cui, J. Liang, G.-N. Li, New. J. Chem., 2015, 39(8), 6025-6033. DOI:10.1039/C5NJ00975H

12. G.-N. Li, C.-W. Gao, H.-H. Chen, T.-T. Chen, H. Xie, S. Lin, W. Sun, G.-Y. Chen, Z.-G. Niu, Inorg. Chim. Acta, 2016, 445, 22-27. DOI:10.1016/j.ica.2016.02.009

13. T. L. H. Doan, L. H. T. Nguyen, T. T. Nguyen, H. L. Nguyen, P. H. Tran, Catalysis Science \& Technology, 2017, 7(19), 43464350. DOI:10.1039/C7CY01668A

14. X. Y. Yu, L. Deng, B. Zheng, B. R Zeng, P. Yi, X. Xu, Dalton Trans, 2013, 43(4), 1524-1533.

DOI:10.1039/C3DT51986D

15. C.-H. Cheng, U.S. Pat. Appl. Publ. 20080217606, 11 Sep 2008.

16. CrysAlisPro Version 1.171.36.21; Agilent Technologies Inc., Santa Clara, CA, USA, 2012.

17. G. M. Sheldrick, Acta Cryst. 2008, A64 112-122. DOI: $10.1107 /$ S0108767307043930

18. O. V. Dolomanov, L. J. Bourhis, R. J. Gildea, J. A. K. Howard, H. J. Puschmann, Appl. Crystallogr. 2009, 42, 339-341. DOI:10.1107/S0021889808042726

19. M. J. Frisch, G. W. Trucks, H. B. Schlegel, Gaussian 09, Revision A.01, Gaussian, Wallingford, Con, USA, 2009.

20. C. D. Sunesh, K. Shanmugasundaram, M. S. Subeesh, R. K. Chitumalla, J. Jang, Y. Choe, ACS Applied Materials \& Interfaces, 2015, 7(14), 7741-7751.

DOI:10.1021/acsami.5b00875

21. G. J. Zhou, Q. Wang, C. L. Ho, W. Y. Wong, D. G. Ma, L. X. Wang, Z. Y. Lin, Chem. Asian. J. 2008, 3, 1830-1841. DOI:10.1002/asia.200800074

22. N. M. Shavaleev, F. Monti, R. Scopelliti, A. Baschieri, L. Sambri, N. Armaroli, Organometallics, 2013, 32(2), 460-467. DOI:10.1021/om300894m

23. M. Y. Wong, G. Xie, C. Tourbillon, M. Sandroni, D. B. Cordes, A. M. Z. Slawin, I. D. W. Samuelb, E. Zysman-Colman, Dalton Trans. 2015, 44, 8419-8432. DOI:10.1039/C4DT03127J

24. V. Chandrasekhar, B. Mahanti, P. Bandipalli, K. Bhanuprakash, Inorg. Chem. 2012, 51, 10536-10547. DOI:10.1021/ic300694m

25. K. A. King, P. J. Spellane, R. J. Watts, J. Am. Chem. Soc. 1985, 107, 1431-1432. DOI:10.1021/ja00291a064

26. G.-N. Li, S.-B. Dou, T. Zheng, X.-Q. Chen, X.-H. Yang, S. Wang, W. Sun, G.-Y. Chen, Z.-R. Mo, Z.-G. Niu, Organometallics, 2018, 37, 78-86. DOI:10.1021/acs.organomet.7b00740 


\section{Povzetek}

Sintetizirali in karakterizirali smo dve novi kompleksni spojini $\operatorname{Ir}(\mathrm{III})$ : [(bo $)_{2} \operatorname{Ir}\left(\right.$ pzpy)] (2a) in [(bo) ${ }_{2} \operatorname{Ir}($ pzpyz)] (2b) (bo $=2$-fenilbenzo[d]oksazol, pzpy $=2$ - $(1 \mathrm{H}$-pyrazol-3-yl)piridin, pzpyz $=2$ - $(1 \mathrm{H}$-pirazol-3-yl $)$ pirazine $)$. Spojinama smo $\mathrm{z}$ rentgensko strukturno analizo monokristalov določili kristalni strukturi. DFT izračune smo uporabili za interpretacijo lastnosti spojin v povezavi z njunima strukturama. Kompleksa $\operatorname{Ir}(\mathrm{III})$ imata prehod iz vzbujenega stanja ${ }^{3} \mathrm{MLCT} /{ }^{3} \mathrm{LLCT}$ $\mathrm{v}$ zelenem in rumenem območju s kvantnima izkoristkoma v raztopini $\mathrm{CH}_{2} \mathrm{Cl}_{2}$ pri sobni temperaturi $35,2 \%$ in $46,1 \%$. Rezultati teoretičnih izračunov in eksperimentalni podatki kažejo, da sta kompleksa $\operatorname{Ir}(\mathrm{III})$ (2a in 2b) obetajoča fosforescenčna materiala. 